\title{
A Long-Term Vision on Faculty Diversity at UC Davis
}

\author{
Raquel E. Aldana and Josephine M. Moreno
}

\begin{abstract}
The sustainability of ADVANCE, beyond its early successes at UC Davis, largely depends on whether it can propel the types of transformational changes needed to fulfill ADVANCE's own aspirations. One of these aspirations is to change the face of STEM at UC Davis. Transformational change must consider the pipeline of Latinx and other underrepresented students into all doctoral programs, including but not limited to STEM. This chapter addresses the need to expand on the ADVANCE initiative to grow the pool of doctoral underrepresented minority (URM) students at UC Davis and nationally, as well as to promote their integration into successful careers after graduation, as professors, scientists, or professionals who go on to become leaders in government or industry. At UC Davis, these efforts have already begun in earnest and include visionary changes to revamp recruitment practices for graduate students, transform graduate admissions practices, and improve mentoring of students during and after completion of their programs. This chapter explores these efforts at UC Davis and summarizes the lessons learned from their implementation.
\end{abstract}

Keywords Graduate student • Holistic review • Graduate admissions • Faculty pipeline $\cdot$ Diversity $\cdot$ Equity $\cdot$ Inclusion

\section{A Brief History of the Academic Diversity Project at UC Davis}

At UC Davis, the project of diversifying the faculty began about two decades ago and intensified considerably with the support of a National Science Foundation ADVANCE grant in 2012. The ADVANCE grant allowed us to institute a series of innovations that have steadily advanced our academic diversity goals. The hiring of underrepresented minority (URM) persons - that is, members of groups that have

R. E. Aldana $(\bowtie)$

School of Law, University of California, Davis, Davis, CA 95616, USA

e-mail: realdana@ucdavis.edu

J. M. Moreno

Graduate Studies, University of California, Davis, Davis, CA 95616, USA

(C) The Author(s) 2022

L. F. Bisson et al. (eds.), Uprooting Bias in the Academy,

https://doi.org/10.1007/978-3-030-85668-7_6 
been denied access or who suffered past institutional discrimination-as ladderrank faculty occurred sporadically and with modest results before 1996, the year that California voters adopted Proposition 209. Prop 209 banned discrimination and prohibited affirmative action programs that use race and other factors such as gender in academic hiring. In academic diversity profiles at UC Davis, we have generally included in the URM definition ladder-rank faculty who identify as Black/African American, Native American, and Latinx/Chicanx (See the UC Davis Diversity \& Inclusion Strategic Vision, 2017).

Within a few years after the adoption of Prop 209, then-Chancellor Larry Vanderhoef expressed to the Academic Senate at UC Davis his concern about significant decreases in the hiring of women. He asked schools and colleges alike to recommend strategies both for increasing the hiring of women and minorities and for improving campus climate (Rockwell, 1999). Women made up 16\% of hires in 1997-98; those figures rose to $40 \%$ in the early 2000 s, then bounced around until recently when they stabilized somewhat.

Women currently make up between 45 and 51\% of hires. Between 1997 and 2016, the proportion of hires that were people of color (a term that includes faculty of Asian descent) has ranged widely between 18 and $41 \%$. Recent reports disaggregate the picture further. During the recent recruitment period of 2011-2016, most schools hired a higher proportion of people of color than were actually available in the workforce. Individual differences exist between colleges in terms of the proportion of applicants versus interviewees. In most professional schools and colleges within UC Davis, women applicants and Black/African American applicants lagged behind availability. By the time of their interviews, the proportion of women again resembled the availability pools, but the same was not true for Black/African American interviewees who continued to lag behind. In turn, this resulted in small numbers of Black/African American candidates hired. For almost all colleges and schools, the proportion of Latinx/Chicanx applicants, interviewees, and hires exceeded their proportion in the pool. UC Davis received its NSF-ADVANCE grant in 2012, and the success in hiring Latinx/Chicanx candidates is due to the Center for Advancing Multicultural Perspectives in Science (CAMPOS) that constituted an important initiative under the grant.

\section{Challenges in Diversifying Faculty}

Despite these steady and recent gains, progress toward diversifying the faculty at UC Davis has been frustratingly slow and has failed to keep pace with either the growing diversity in California or the changing composition of the student body. In 2018, UC Davis's undergraduate student profile consisted of 31\% Asian, 23\% White, 22\% Latinx, 17\% International, 4\% Black/African American, and 1\% Native American. Yet, the corresponding statistics for UC Davis ladder rank faculty for 2018 was 14\% Asian, 54\% White, 5\% Latinx/Chicanx, 20\% International, 3\% Black/African American, $1 \%$ Two or More Races, and $<1 \%$ American Indian (Figs. 1 and 2). 

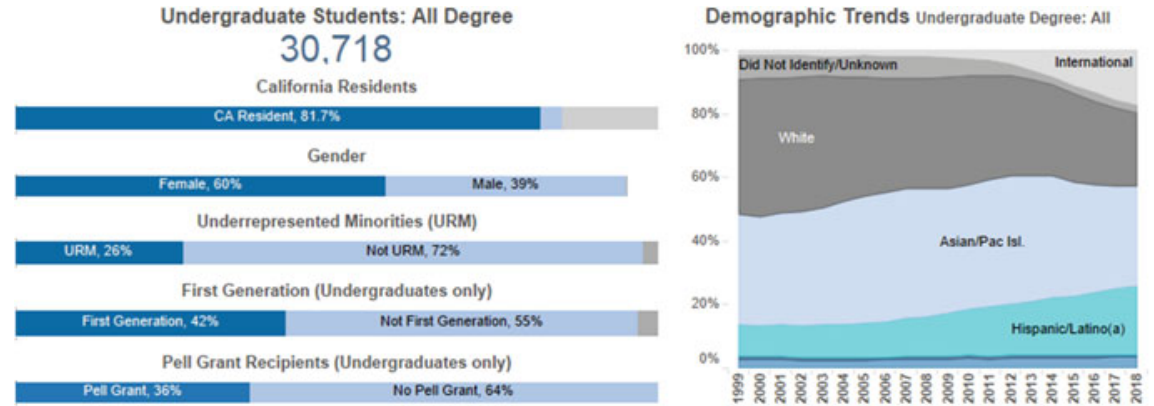

Fig. 1 UC Davis Fall 2018 enrollment of undergraduate students: residency, gender, first gen, pell recipients, and race/ethnicity. Source UC Info Center

UC Davis's slow progress toward diversifying the faculty has various explanations. One is the campus's legacy of having a predominantly white ladder-rank faculty, which means that opportunities to diversify the faculty depend largely on the availability of new hires. Alternatively, the number of new faculty hires can also depend on openings that arise from faculty attrition, such as departures or retirements, or accommodations made for student growth whenever funding is available. At UC Davis, growth driven by undergraduate students has not been an issue. In 2018, a record 95,207 applicants sought admission into UC Davis as freshmen or transfer students; consequently, UC Davis's enrollment capacity of 39,000 has been easily met (May, 2018a). In contrast, over the same period, the campus has experienced modest revenue growth (based on small and temporary increases of in-state funding as well as imposed caps on nonresident tuition). Concurrently, campus expenditures have increased as a result of, for example, higher costs of funding salaries and benefits for faculty and staff (May, 2018b). Moreover, UC Davis has experienced a slow pace of ladder-rank faculty departures or retirements (Kaskle et al., 2012).

Once hired, faculty at UC Davis tend to stay for many years. The dates at the bottom of Fig. 3 represent the dates of hire for all ladder faculty currently working at UC Davis and show that although the campus has been hiring with greater diversity in recent years, the legacy of homogeneity in the academic pool has a long-lasting effect. The dates of hire for those faculty working at UC Davis in 2018 reach back to 1966 with nearly $11 \%$ of those who remain (185 of 1711) having stayed 30 years or longer and another $17 \%$ of those who remain (291 of 1711) having stayed between 20 and 30 years.

The combination of slower-than-predicted capacity to hire new faculty to accommodate student growth, plus the sluggish pace of retirements, has resulted in fewer opportunities to diversify the faculty through new hires (Figs. 4 and 5).

A second important explanation for the slow progress in diversifying the UC Davis faculty is the lack of diversity in the available pool for ladder-rank academic hires, particularly among new URM and women Ph.D.'s working in STEM fields. The diversity of the availability pool among graduate students unfortunately lags behind national, state, and campus demographics (Fig. 6). Nationally, over 54,000 people 


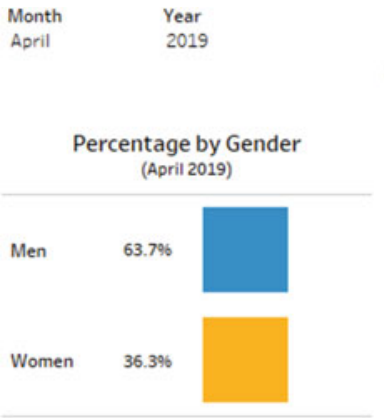

Percentage by Race/Ethnicity \&

\begin{tabular}{|c|c|c|}
\hline \multirow{2}{*}{ White } & Domestic & 58.096 \\
\hline & International & 12.190 \\
\hline \multirow{2}{*}{$\begin{array}{l}\text { Asian/Native } \\
\text { Hawaiian }\end{array}$} & Domestic & 8.796 \\
\hline & International & $7.3 \%$ \\
\hline \multirow{2}{*}{$\begin{array}{l}\text { Hispanic/ } \\
\text { Latino(a) }\end{array}$} & Domestic & $3.8 \%$ \\
\hline & International & 2.896 \\
\hline American Indian & Domestic & 0.596 \\
\hline $\begin{array}{l}\text { Black/African/ } \\
\text { African }\end{array}$ & Domestic & $1.6 \%$ \\
\hline American & International & $0.6 \%$ \\
\hline \multirow{2}{*}{$\begin{array}{l}\text { Two or More } \\
\text { Races }\end{array}$} & Domestic & 0.396 \\
\hline & International & 0.196 \\
\hline \multirow{2}{*}{ Unknown } & Domestic & $2.8 \%$ \\
\hline & International & $1.4 \%$ \\
\hline
\end{tabular}

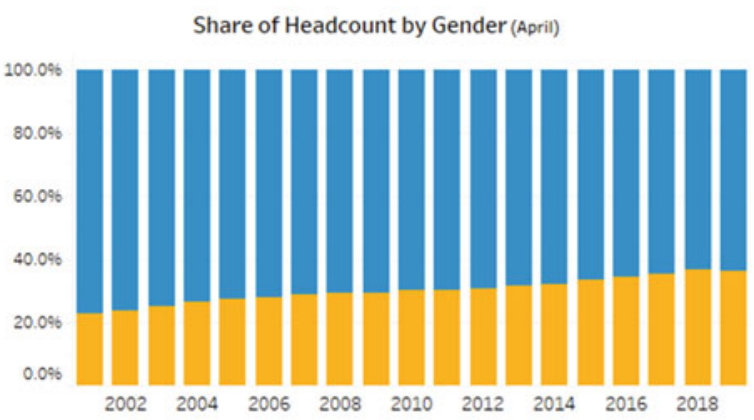

Share of Headcount by Race/Ethnicity \& Citizenship (April)

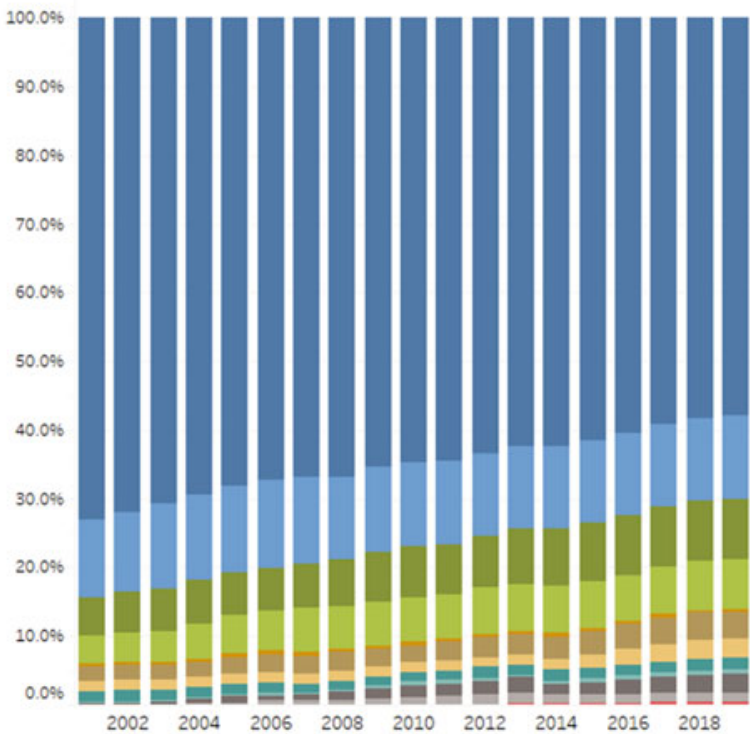

Fig. 2 UC Davis April 2019 ladder-rank faculty profile: gender and race/ethnicity and citizenship. Source UC Info Center

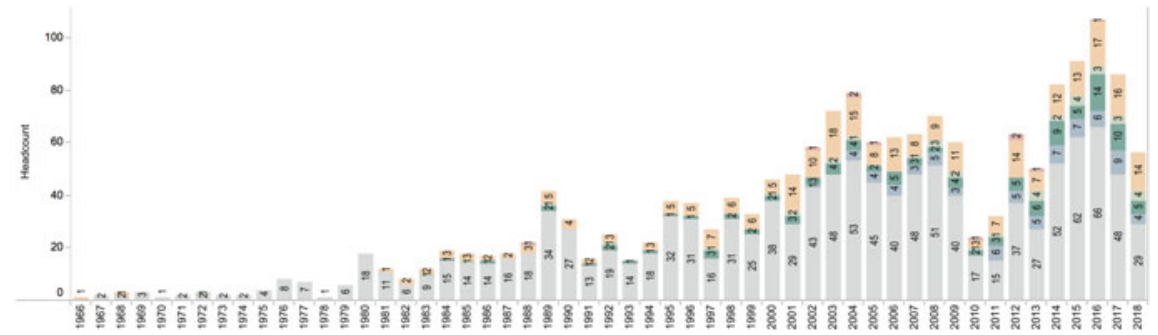

Fig. 3 Hiring year snapshot for UC Davis ladder faculty employed on October 2018 (with ethnicity). Source UC Davis academic affairs/budget and institutional analysis 


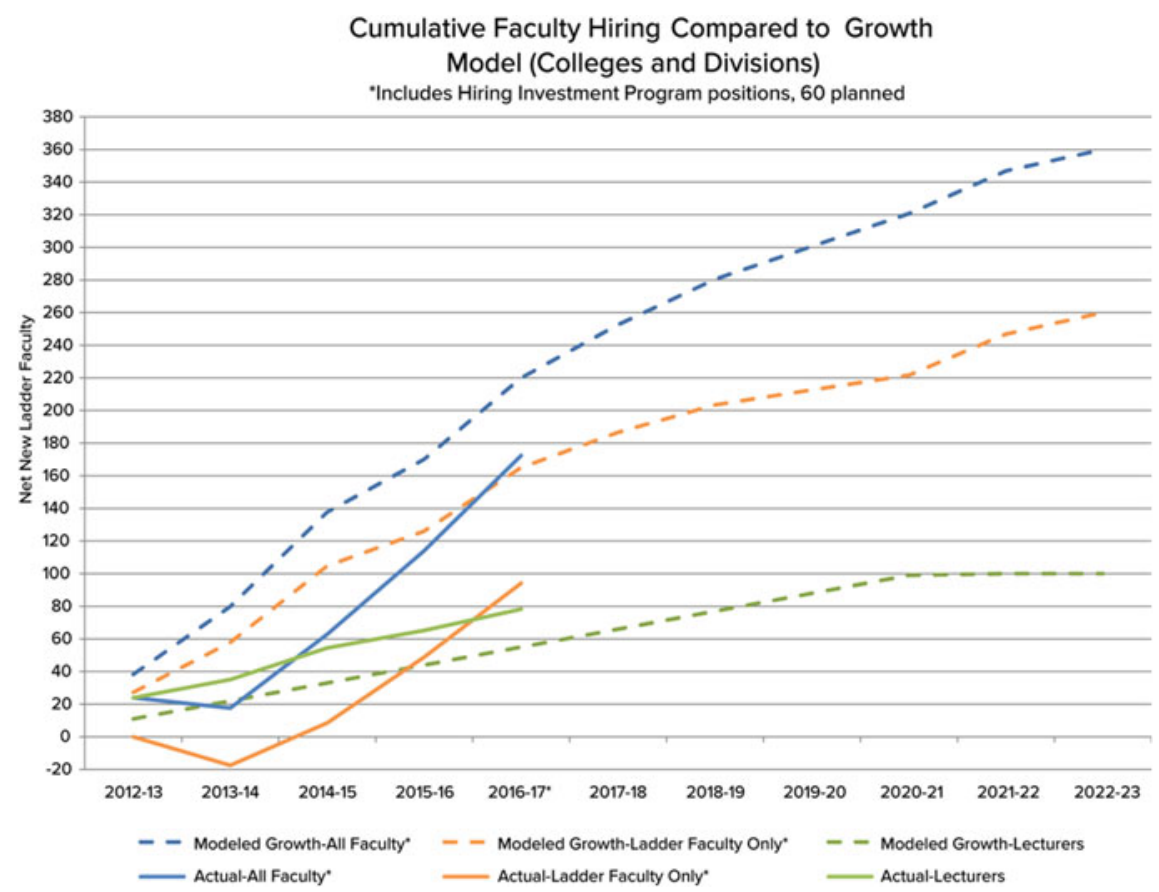

Fig. 4 Ladder faculty recruitment and hiring trends, colleges, as of 2017. Source Budget overview: 2017 new department chairs workshop, September 19, 2017, by Ralph Hexter and Sarah Mangum

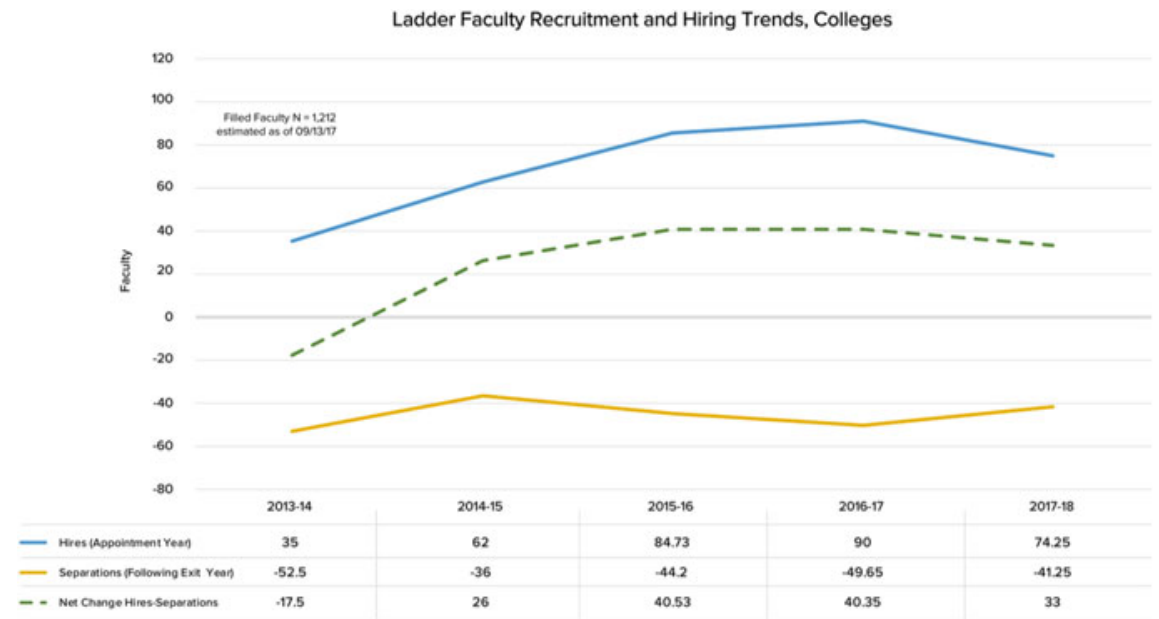

Fig. 5 Cumulative faculty hiring compared to growth model as of 2017 (colleges and divisions). Source Budget overview: 2017 new department chairs workshop, September 19, 2017, by Ralph Hexter and Sarah Mangum 
Doctorates awarded to minority U.S. citizens and permanent residents, by race, ethnicity, and broad field of study: 2017
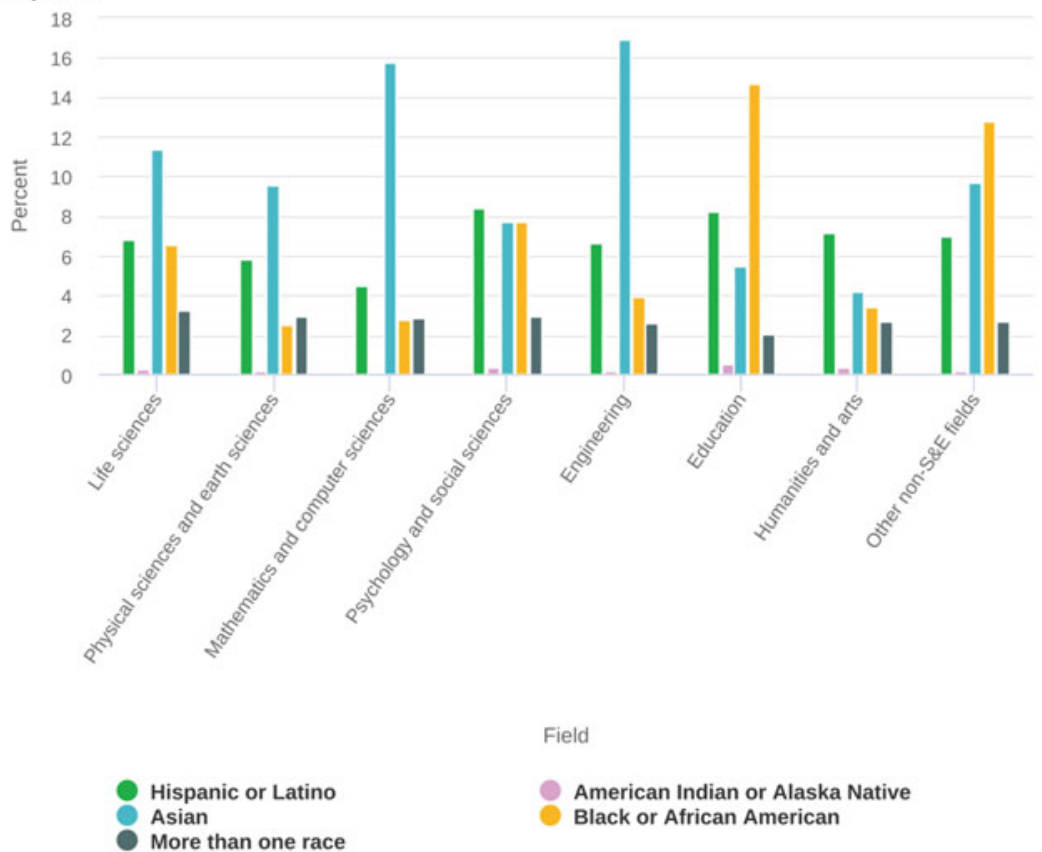

$\mathrm{S} \& \mathrm{E}=$ science and engineering .

Note(s)

Hispanic or Latino may be any race. Missing data have been suppressed for reasons of confidentiality.

Source(s)

National Science Foundation, National Center for Science and Engineering Statistics, Doctorate Recipients from U.S. Universities: 2017. Related detailed data: table 23 and table 24.

Fig. 6 Doctorates awarded to minority U.S. citizens and permanent residents by race, ethnicity, and broad field of study: 2017. Source National Science Foundation, National Center for Science and Engineering Statistics. 2018. Doctorate Recipients from U.S. Universities: 2017. Special Report NSF 19-301. Alexandria, VA. Available at https://ncses.nsf.gov/pubs/nsf19301/

earned doctorates in 2017, a growth of more than 10,000 over the past 10 years. Of those, 5\% (2540) were earned by people who identified as Latinx/Chicanx, 4\% (2409) as Black/African American, and under 1\% (103) by American Indian or Alaska Native (Fig. 6). Thus, to fully comprehend the academic diversity project in American higher education at large, it is imperative to consider the development of URM doctoral students.

\section{UC Davis Interventions and Innovations in Hiring and Retention}

For more than a decade, UC Davis has committed to hiring faculty coming from diverse backgrounds, achieving this by instituting several significant, process-based interventions. These interventions have included mandatory diversity statements from all applicants, monetary incentives, and mandatory implicit bias training for 
faculty hiring committees. Additionally, an Associate Vice Provost for Equity and Inclusion reviews all shortlists to ensure that those invited to interview reasonably reflect the diversity of the available pool of applicants as measured by the number of Ph.D.'s in the field (Fig. 7).

In 2018-2019, based on a grant from the University of California to advance academic diversity, UC Davis adopted several additional innovations to improve the hiring process. Among these are efforts to conduct open searches targeting faculty committed to embracing campus diversity and inclusion values, and to start the selection of candidates with an assessment of the diversity statement (see https://academ icaffairs.ucdavis.edu/advancing-faculty-diversity-pilot-project). Early results show their great promise to increase the pool of faculty of color across many fields.

\section{INTERVENTIONS IN THE ACADEMIC HIRING PROCESS}

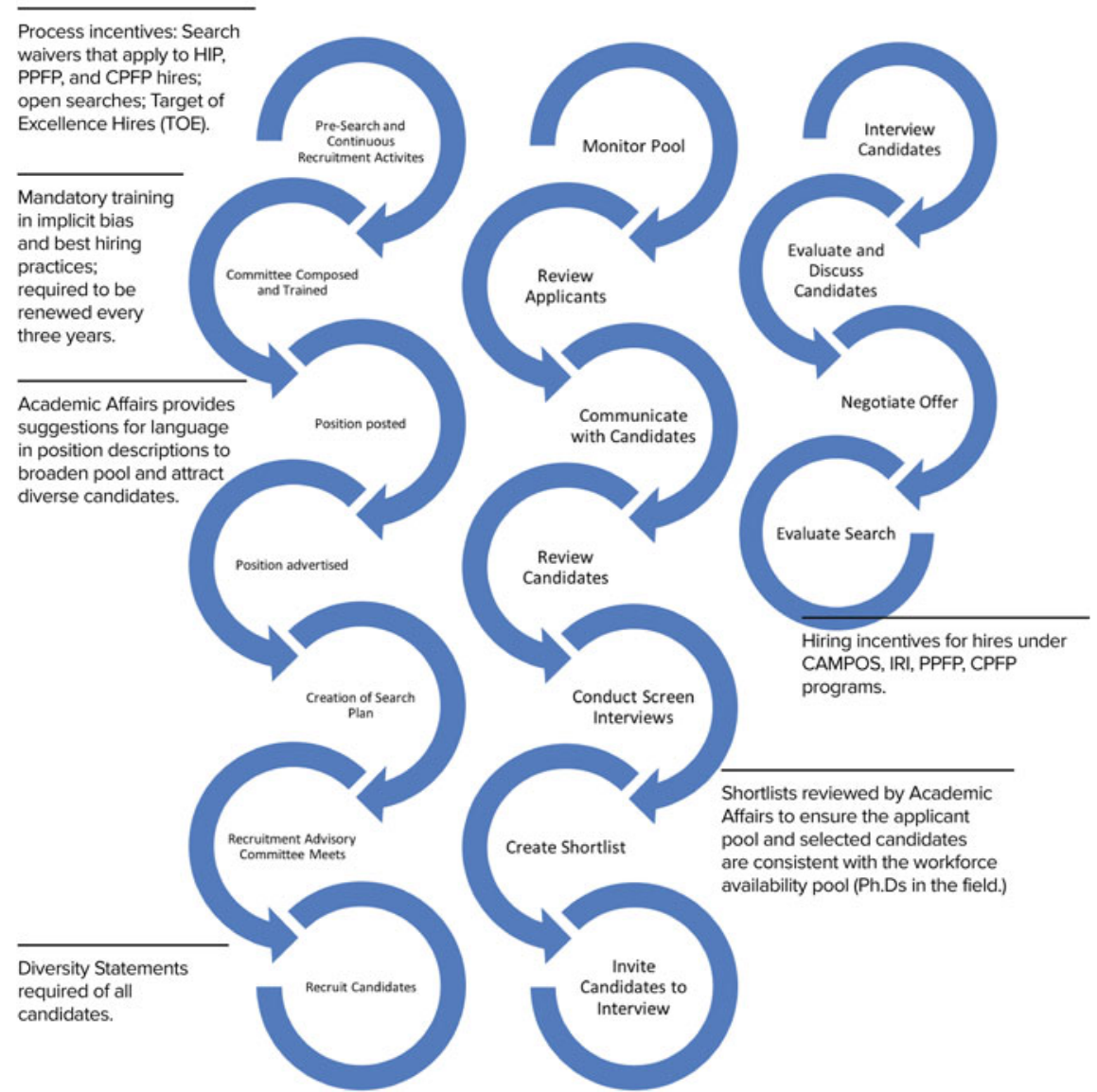

Fig. 7 Current interventions to promote diversity in the academic hiring process 
In response to the representational imbalance of Latinx/Chicanx in STEM education (White House Initiative on Educational Excellence for Hispanics, 2014), the National Science Foundation encouraged UC Davis to focus its ADVANCE grant on expanding the representation of Latina faculty in STEM. Accordingly, over the last eight years since the implementation of ADVANCE, UC Davis has hired 25 faculty across 20 STEM academic disciplines whose research, teaching, and service bring multicultural perspectives to science. (For a full list of CAMPOS scholars, visit https://diversity.ucdavis.edu/scholars). More than $50 \%$ of the new hires are Latinx/Chicanx and overwhelmingly women. This is a significant achievement given UC Davis's starting place in 2012 when only 33 Latinx/Chicanx (4\%), 16 other URM (2\%), 134 Asian (15\%), and 238 women (26\%) were among the 919 ladderrank faculty who taught in either the College of Agricultural and Environmental Sciences, the College of Biological Sciences, the College of Engineering, or the Divisions of Math and Physical Sciences and Social Sciences (representing most of the disciplines considered science, technology, engineering, and math, or STEM). Nonetheless, Latinx/Chicanx, URM, and female faculty remain disproportionately underrepresented among STEM faculty at UC Davis. Today, in 2019, at UC Davis, 52 Latinx/Chicanx (5\%), 24 other URM (2\%), 167 Asian (16\%), and 327 female (32\%) ladder-rank faculty are among the 1038 ladder-rank faculty in these same colleges and divisions.

\section{Connecting the Hispanic Serving Institution (HSI) Project at UC Davis to the Academic Diversity Project Through the HSI Graduate Pipeline}

The history of Hispanic ${ }^{1}$ Serving Institutions (HSI) represents a move toward equity for Latinx/Chicanx students in higher education. In contrast to Historically Black Colleges and Universities (HBCU), HSIs, as defined under federal law, relate the "fit" between the demographics of the local population and the demographics of the student body in the region's colleges and universities (Laden, 2001). According to federal law, HSIs comprise colleges and universities that (1) are an eligible institution; and (2) have an enrollment of undergraduate full-time equivalent students that is at least $25 \%$ Hispanic at the end of the award year immediately preceding the date of application (Title 20_Education, 2015).

Eligibility is determined by two factors: (1) enrollment of at least half of HSI students who are also low income (eligible for need-based financial aid) and (2) who also demonstrate low resources as measured by a comparison of per-undergraduate student expenditure of the institution seeking eligibility, as compared to the national average per-undergraduate student expenditure at similar institutions (Title 20Education, 2015). Moreover, colleges and universities applying for HSI eligibility

\footnotetext{
${ }^{1}$ Hispanic, Latino/a, Latinx and Chicanx are used interchangeably. All refer to persons of Latin Amerian or colonial Spanish heritage.
} 
may seek a waiver of the second factor but not the first (Eligibility Designations \& Application for Waiving Eligibility Requirements, 2019). The determination of the threshold enrollment numbers relies on the methodology employed by the Integrated Postsecondary Education Data System (IPEDS), maintained by the Center for Education Statistics (NCES). IPEDS uses a methodology that filters Latinx/Chicanx students into three separate categories based on their immigration status. Only those eligible for financial aid under federal law, including U.S. Citizens and lawful permanent residents, are classified as "Hispanic/Latino." In contrast, DACA students (in the Deferred Action for Childhood Arrivals program) are classified as "Nonresident Aliens," while undocumented students are filtered into a category of "No Race/Race Unknown" (IPEDS Data Collection System, 2019-20).

Narrowly focused, HSIs direct federal funding opportunities to undergraduate education at under-resourced institutions. An entire body of scholarship exists today that has shifted the HSI framework to more-robust conceptions of equity or service (Garcia, 2018). UC Davis, in developing a set of values related to its own HSIinitiative, also borrowed the term "Rising Scholars" to describe the full range of students who might benefit from our efforts and to signal a move away from a "student deficit" framework toward one that embraces institutional transformation and acknowledges the cultural and personal assets that students bring to our campus. The "Rising Scholars" initiative also suggests that, as HSIs have grown $98 \%$ in the past 10 years to 523 colleges and universities (2017-18), they have begun to occupy even elite spaces in higher education, shifting the academy toward defining what the role of research-intensive HSI institutions can and should be.

Most of the $17 \%$ of all institutions that meet the HSI definition are small (62\% of HSIs enroll fewer than 5000 students). Public two-year institutions make up $42 \%$ of HSIs, whereas public four-year institutions make up 25\%. Most of these institutions are located in California, Texas, Puerto Rico, and New York (69\% together). At HSIs, $46 \%$ of undergraduate students are Latinx, while $66 \%$ of college-going Latinx attend an HSI. Only the following 14 institutions are HSIs which, according to their Carnegie Classifications of Research Institutions, also have very high research activity (denoted R1) (Fig. 8).

Even though UC Davis is not yet formally designated a HSI, in fact it serves more "Hispanic" students (6361 in 2017-18) than do HSI-designated R1's UC Santa Barbara (5851), UC Santa Cruz (5851), University of Illinois at Chicago (6058), University of Nevada Las Vegas (6215), and CUNY Graduate School and University Center (352) (Excelencia in Education, 2019; IPEDs, Carnegie Classifications). The impact of R1s on the HSI landscape has significant potential, in part because of the large numbers of students that these institutions educate.

The entire University of California system, which boasts a total of five HSIs, can play an important role in contributing to the academic diversity pipeline for its 10 campuses. It can also link our academic faculty diversity project to key goals such as increasing a sense of belonging, teaching excellence, research innovation, and public service-all of which attempt to fulfill UC Davis's original land grant mission to serve the diverse peoples of the state. In addition to the campuses listed above, UC Merced is a HSI (but is considered an "R2," according to Carnegie Classifications). UCLA, 


\section{HSI Institutions}

- University of Arizona (Tucson, AZ)

- University of California-Irvine (Irvine, CA)

- University of California-Riverside (Riverside, CA)

- University of California-Santa Barbara (Santa Barbara, CA)

- University of California-Santa Cruz (Santa Cruz, CA)

- Florida International University (Miami, $\mathrm{FL})$

- University of Illinois at Chicago (Chicago, IL)

Fig. 8 List of HSI research institutions

UC San Diego, and UC Davis are each emerging HSIs and have come very close to reaching the full status. UC Berkeley also recently announced its commitment to attain HSI status in the next decade. The only campus not technically eligible for HSI status under the narrow federal definition is UC San Francisco, since it is largely a graduate and professional school.

As the UC-wide vision to become "Hispanic-Serving" is constructed, graduate and professional education are likely to be included. In 2013, 66 of 370 HSIs offered doctoral degrees; in 2017-18, 119 now offer doctoral degrees, with 54 located in California, the most of any other state (Excelencia in Education, 2019). While the number of HSIs offering graduate programs is growing, the key to understanding the pipeline to faculty careers is the actual number of Latinx students who go on to pursue doctoral degrees. Thus, the pipeline begins with undergraduates who earn bachelor's degrees and who later enter doctoral programs where the pipeline narrows considerably, allowing even smaller numbers of Latinx students the privilege of pursuing the highest possible levels of education.

The growing Latinx population in the United States and Puerto Rico drives the pool of applicants to all doctorate-granting institutions, including UC Davis; yet only a small proportion of that population makes it to college, goes on to earn a bachelor's degree, and eventually advances into a graduate program.

- Of the total U.S. population of 326 million, $18 \%$ or 59 million, identify as "Hispanic.," (https://factfinder.census.gov/faces/tableservices/jsf/pages/productview. xhtml? src=bkmk, Drawn on April 25, 2019).

- In the United States, 48 million persons 25 and older, or 14\%, held a bachelor's degree in 2018 (U.S. Census Bureau, 2019).

- "Hispanics" holding bachelor's degrees numbered only 4.4 million: $9 \%$ of all bachelor's degree holders, $7 \%$ of 59 million Hispanics, and only $1 \%$ of the total U.S. population. 


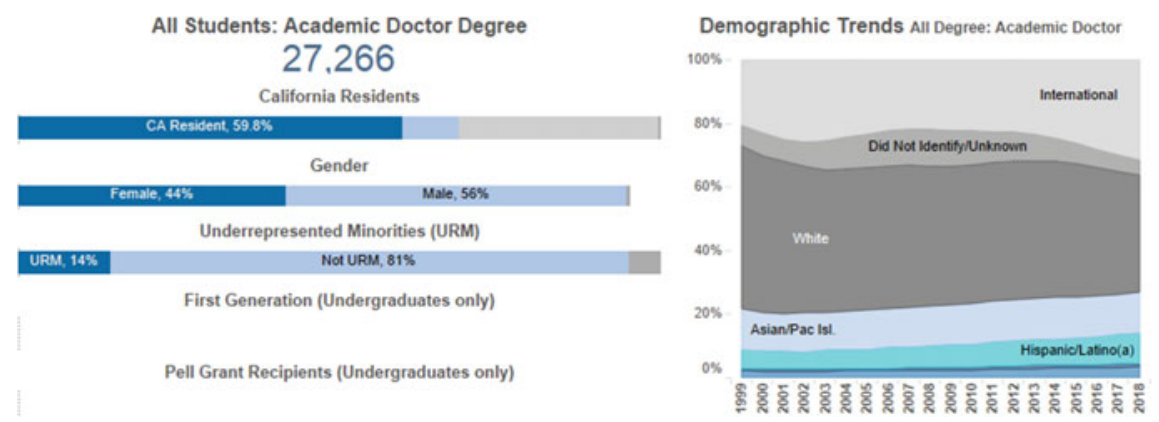

Fig. 9 UC Davis fall 2018 enrollment of graduate academic students: residency, gender, and race/ethnicity. Source UC Info Center

These degree holders comprise the domestic pool who apply to graduate school. The same 2018 U.S. census data report that a mere 193,000 Hispanics hold doctoral degrees. These few Latinx scholars who actually pursue and successfully earn doctoral degrees contribute to a very narrow pipeline available to grow the numbers of Latinx faculty.

The University of California offers nearly 500 doctoral programs in all major fields of study, nearly all of which are classified at the highest levels of research activity by the Carnegie Classification of Research Institutions. Within the UC system, the number of students educated is truly impressive. In fall 2018, more than 280,000 students were enrolled across all higher-education levels, of which $26 \%$ identified as URM and $21 \%$ as Hispanic/Latino(a) (UCOP, 2019) (Fig. 9). Further delineated, UC educated more than 222,000 undergraduate students, of which $29 \%$ identified as URM and $22 \%$ identified as Hispanic/Latino(a). In academic doctoral programs, that is, those programs considered most likely to be pathways to the professoriate, 27,266 were enrolled. Of those, $14 \%$ identified as URM and $10 \%$ identified as Hispanic/Latino(a). The "leakiness" of the pipeline is concerning, but the number of URMs in the academic pipeline, at just over 3800, nonetheless affords an increasing sense of belonging among URM graduate students and later advancement into faculty and researcher roles (UCOP, 2019). Academic doctoral programs also attract a high number of international students to the UC system: $31 \%$ in 2018 . While international students may have different challenges and pathways, their participation adds to the overall diversity of UC graduate programs.

In the last two decades, the University of California has also trained tens of thousands of health professionals in the state, including thousands who are health professionals of color. The following link provides an interactive chart of all the UCeducated health professionals in California, broken up by field and demographics that include race and ethnicity: https://www.universityofcalifornia.edu/infocenter/ uc-health. Moreover, five of the 21 American Bar Association-accredited law schools in California are part of the University of California; in 2018, combined, they enrolled nearly 1400 students, almost half of whom were students of color. For a list of California law schools, visit http://www.calbar.ca.gov/Admissions/Law-School-Regula 
tion/Law-Schools. Consider the student profiles data reported by each of the five UC law schools for their entering classes in 2018: UC Berkeley has 314 students, 46\% students of color; UC Davis has 206 students, 53\% students of color; UC Hastings has 313 students, 48\% students of color; UC Irvine has 229 students, $50 \%$ students of color; and UCLA has 311 students and $41 \%$ students of color. As well, the number of UC-trained California public school teachers is nearly 30,000, over half of whom teach in lower-income schools and collectively teach more than two million students (https://www.universityofcalifornia.edu/infocenter/uc-trainedcalifornia-public-school-teachers).

Thus, the University of California system plays an important role in increasing the diversity of the academic pipeline nationwide. UC Davis is an example of only one institution that Latinx and other URM students may select to pursue a doctoral degree. The UC system is not only considered a driver of innovation, but also a means of social mobility, educating large numbers of first-generation college-goers, children of immigrants or the economically disadvantaged. Today UC Davis offers far more than its original agricultural and "mechanical arts" training. Contemporary strengths include agricultural and environmental sciences, biological sciences, education, engineering, health sciences, letters and sciences, management, and veterinary science fields.

The establishment of additional HSIs in California and across the United States speaks to the significant needs of the Latinx population throughout the country. Moreover, given the small number of research-intensive institutions that are HSIs, contextualizing UC Davis among its HSI counterparts demonstrates a nuanced understanding not only of the specific issues one institution faces but also of issues and opportunities among research universities that educate large numbers of Latinx students.

\section{Implications of UC Davis's HSI Initiative on Academic Diversity and Graduate Pathways to the Professoriate}

The process of envisioning what HSI status would mean for UC Davis as a land-grant research-intensive university was launched in July 2018 when Chancellor May established the HSI Taskforce. The taskforce was charged with making recommendations to improve the success of all UC Davis students, including UC Davis Latinx/Chicanx students, and to identify the reforms and resources necessary to achieve these goals. It completed the report on March 29, 2019, which was publicly released on May 7 , 2019. The Taskforce organized its 52 recommendations under four principal goals:

1. Prepare and attract to UC Davis a broad profile of Rising Scholars (a term we adopted from White (2016), to embrace an asset-oriented view of students who are first-generation college students, URM, and/or low-income),

2. Ensure that Rising Scholars have the opportunity to learn, succeed, graduate, and thrive, 
3. Fulfill UC Davis' Hispanic Serving mission by elevating students to industries with critical workforce needs, preparing and educating all students to serve in a multicultural society, and

4. Harness the collective strengths of the University of California as a system to transform higher education.

Each of these goals and recommendations, moreover, was grounded in four important values and the guiding principle that institutional transformation would acknowledge UC Davis's legacy as a predominantly white, elite institution which has largely operated to marginalize the very students now being classified as Rising Scholars. In other words, the HSI Taskforce report sought to reexamine and address institutional structures and practices — such as implicit bias and lack of diversity - that have served as barriers to success for these students.

The first value rested on equity as informed by Chicanx/Latinx demographics in the state of California, the unique civil rights history of that population in the state, and the persistent disparities in nearly all the social indicators for Chicanx/Latinx communities (Aldana \& Reed, 2019). The second value rested in the use of the term "Rising Scholars" to refer to the profile of HSI students-largely first-generation college students, low income, and URM - and intentionally shifts away from deficitthinking explanations of academic achievement gaps and toward structural explanations; i.e., opportunity gaps versus achievement gaps. The third value was informed by an extensive literature connecting a sense of belonging to academic achievement for URM groups. And last, the fourth value stems from UC Davis's land grant mission, which encompasses serving rural and underserved communities through teaching, research, and service. As the Report states,

Through the HSI initiative, we envision UC Davis as a culturally responsive learning community that fulfills the mission of a Research 1 and land grant university, closing the equity gap in higher education; enabling all of its community members, including Rising Scholars, to thrive and reach their full potential; and elevating our excellence in public service and scholarship. (Aldana \& Reed, 2019, p. 7)

A few of the recommendations that highlight the centrality of the academic diversity project to the UC Davis HSI vision are as follows:

- Commit to increasing the number of Rising Scholars who enter graduate and professional programs by (1) supporting the implementation of holistic admission practices across all graduate and professional programs and groups that desire to recalibrate their admissions practices; (2) creating and resourcing a role in Graduate Studies charged with developing outreach and recruitment strategies for bringing Rising Scholars into graduate programs; and (3) collaborating with the University of California Office of the President (UCOP) to establish formalized efforts to reach and recruit Rising Scholars across all 10 campuses for graduate programs (Aldana \& Reed, 2019, p. 53);

- Establish institutional incentives to empower faculty and staff with the skills they need to effectively teach, mentor, innovate, lead, and build positive campus climates and learning environments by, among other things: sustaining Rising 
Scholars in the pipeline to the professoriate, supporting the conditions for teaching innovation, and building a framework (either inside or outside the current budget model) for public scholarship and research that places a value on high-touch, high-impact outcomes for Rising Scholars (Aldana \& Reed, 2019, p. 55);

- Fulfill our Hispanic Serving mission by elevating students to industries with critical workforce needs and by preparing and educating all students to serve a multicultural society. This requires, among other things, (1) creating bridges between communities and academic departments to position our students, alumni, and faculty to meet the needs of under-resourced communities and industries and (2) working with students, faculty, and staff to cultivate compassion, humility, and social awareness (Aldana \& Reed, 2019, p. 57); and

- Harness the University of California collective strengths as a system to transform public education by, among other things, (1) developing a 10-campus Rising Scholars "pathways to the professoriate" initiative that innovates around outreach to undergraduate students, holistic admissions to graduate programs, outreach to graduate students, and incentivizing postdoctoral fellowship programs, and (2) addressing the ongoing crisis in representation of Chicanx/Latinx faculty by increasing funding for existing recruitment and hiring strategies (Aldana \& Reed, 2019, p. 58).

Many of these recommendations align several other important strategic vision plans at UC Davis, including Chancellor May's "To Boldly Go" Strategic Plan and the UC Davis Diversity and Inclusion Strategic Vision (Aldana and Reed, pp. 62-63). More important, many significant initiatives are under way at UC Davis that complement the recommendations mentioned above, and others are now being explored.

The remaining portions of this chapter will focus mostly on UC Davis efforts todate to sustain the academic pipeline, situating it in the context of our HSI framework. Also, we intentionally address some of the barriers that persist and must be overcome if we are to reevaluate our present and reimagine our future. Where are we now in achieving some of the recommendations identified above, and where do we want to be?

\section{Challenges in Diversifying Graduate Programs}

The ADVANCE program, which focused on diversifying UC Davis faculty, has received increasing attention, as have programs that require faculty hiring committees to be trained in equitable and inclusive hiring practices. Moreover, the increasing diversity among undergraduates is promising, particularly for California's large Latinx population. However, the link to faculty diversity depends on training graduate students from diverse backgrounds. A significant challenge here is that the pipeline narrows as URMs apply, are admitted, and eventually accept admission offers, with the number of Latinx applicants decreasing at each step. 
- At UC Davis, the number of applications received from 2009 to 2017 averaged 10,200 per year for academic master and doctoral degrees, increasing from 8,181 to 11,111 during the nine-year period.

- Of the total, URM applications averaged 675 over the same time frame, increasing from 415 to 757 , or $5 \%$ and $7 \%$ of the total number of master's and doctoral applications, respectively. The number of URM admissions grew slowly from 2009 to 2017, averaging only 212 a year for academic master and doctoral programs at UC Davis. The totals increased from a low of 129 to 262 during this same nine-year time span.

- Latinx applications numbered 701 in 2017: only 6\% of the total number of 11,111 applications in the same year. In 2017, admissions from the 701 Latinx applications resulted in only 257 admissions, or $8 \%$ of all admissions in the same year. The final outcome is that acceptances numbered only 122, or $10 \%$ of all "yes" responses in 2017.

Latinx admissions in 2017 reflected a very slow increase from previous years, and far fewer than the percentage of the Latinx population in California or United States. The data in this paragraph are drawn from a UCD Graduate Studies' Analysis and Policy report dated April 16, 2019. These data suggest the number of Latinx with bachelor's degrees is growing, but far fewer seek graduate degrees. Moreover, the winnowing effect through personal election and faculty gatekeeping (Posselt, 2016) in the graduate admission process reduces Latinx applicants even further, resulting in the small number of Latinx graduate students who enroll at UC Davis each year.

Enrollment of Latinx graduate students is, of course, not the end-point of developing future faculty; financial considerations and graduate student success also play significant roles. Funding for graduate students is a substantial factor that decreases the number of Latinx persons who enroll if the level of support is not competitive. At UC Davis, graduate students admitted into STEM fields are more likely to be offered a financial "package" that pays fees and tuition (both in-state and nonresident) and that provides a monthly living stipend. However, for many students in humanities, arts, social sciences, and certain other fields, funding consists largely of teaching assistantships during which they devote their time to undergraduate teaching activities, with the payment of fees, tuition, and a stipend governed by collective bargaining. If a graduate student is offered a research assistantship for one or more years, nonresident tuition is also paid as a benefit of employment, particularly for the first year. This situation can be significant for nonresident domestic students who may be expected to pay nonresident tuition while they establish California residency in their first year on campus.

While some university fellowships are offered for all URMs, they are extremely limited, with only 19-23 fellowships awarded to both new and continuing diversity students each year. These are largely single-year fellowships; with only the UC-wide Eugene Cota Robles Fellowship is a multiyear offer that every year awards only 5 or 6 new graduate students two years of support at UC Davis. These graduate funding opportunities demonstrate the tenuous nature of admissions and enrollment that depend on whether Latinx students are offered funding that realistically pays a 
large percentage of their costs to pursue a graduate degree. The financial offer is also a factor in their success in completing their academic master's and doctoral degrees.

In addition to limited availability of fellowships to support Latinx student success, graduate students also face issues such as cohort and peer competitiveness, microaggressive climates, or their own feelings of self-worth, all of which can thwart successful completion of their graduate degrees. Enrolled Latinx graduate students encounter extremely competitive environments among peers. Often the first generation in their family to earn a bachelor's degree, Latinx graduate students may not be aware of presumed, but uncommunicated expectations within their seminars or graduate programs. Students report microaggressive environments that are fraught with assumptions, negative comments, and lack of support by peers and faculty alike for their ideas, personal experiences, research topics, and sometimes even their use of Spanish when it differs from formal, book-learned Spanish. Their personal selfworth can be low at the start, when students compare themselves to others who may speak more formally, have grown up in middle- to upper-middle-class families, or have attended highly-ranked undergraduate institutions. The phenomenon of "stereotype threat" can set in when students perform poorly due to the communication of an expectation of stereotypical low-group performance by others (Steele \& Aronson, 1995). Thus, graduate student success is typically fraught with challenges that must be successfully navigated to attain doctoral degrees in a climate that can be unsupportive and even distinctly negative.

\section{UC Davis Best Practices in Growing and Recruiting the Graduate Pipeline}

With all these challenges to successfully complete graduate school, UC Davis is employing strategies to support Latinx graduate students. In fall 2013, Graduate Studies created and hired two graduate diversity officers (GDOs), professionals who address and coordinate graduate URM recruitment, admission, and retention or success-one officer covering STEM fields and a second for Humanities, Arts, Social Sciences, and Education fields. Since 2013, Latinx graduate applications, admissions, and enrollment have increased 25\%, 40\% and 40+\%, respectively. With Ph.D.'s in hand, experience as tenure track faculty, and many years of professional experience, both of UC Davis' current GDOs are committed to all three aspects of Latinx graduate students' - and, more broadly_-URM success. Facilitating mentorship, holding productive dialogues on race and ethnicity, understanding equity and unconscious bias, and developing grant leadership are cornerstones of their work.

One well-known approach to increasing Latinx doctoral students at UC Davis is to build pipelines by means of formal as well as informal programs and groups. Formal groups allow for direct support of pipeline programs in which Latinx undergraduates participate to learn about graduate school and to experience rigorous preparation for graduate studies. Pipeline programs are common in all disciplines at the state and 
national level, such as California's UC LEADS programs and the Ronald E. McNair Scholars, respectively. At UC Davis, specific graduate preparation programs, such as the Undergraduate Research Program and Mentorships for Undergraduate Research in Agriculture, Letters, and Science (MURALS), include URM undergraduates and prepare them for graduate school. Yet these and other graduate preparation programs reach only a small number of Latinx undergraduates each year, suggesting the need to scale up efforts to train larger numbers of Latinx undergraduates who desire to pursue graduate-level studies.

A second situation is the bias against a homegrown pipeline of Latinx graduate students. Faculty and staff regularly advise UC Davis undergraduates to attend graduate school at another institution in order to develop a more varied educational profile and set of experiences. However, many Latinx student foresee financial and cultural barriers to leaving home that may also reflect professional aspirations of giving back to their communities. Consequently, while UC Davis supports and hosts certain pipeline programs, many UC Davis Latinx students may be reluctant to leave California because of their strong cultural ties. Alternatively, when UC Davis hosts programs that draw students from outside the region to their campus pipeline programs, participants represent a mix of in-state and nonresident students which can increase the number of Latinx applicants from these programs. For example, UC Davis is a partner on the HSI: Pathways to the Professoriate grant, led by PI Marybeth Gasman at Rutgers University. HSI Pathways coordinates three HSIs and six research institutions, collaborating to guide and mentor a total of 30 Latinx students each year. In fall 2019, four HSI Pathways, Latinx scholars selected UC Davis for their doctoral studies among all three of the participating HSI institutions: California State University Northridge, University of Texas El Paso, and Florida International University.

Both examples of pipeline programs represent formal initiatives that develop undergraduate Latinx talent for graduate school. However, "building a pipeline" need not be limited to educating and preparing UC Davis Latinx students for graduate studies; it can also involve coordinating and collaborating within and across larger systems (such as University of California and California State University systems) and even regionally, to encourage the interchange of talented Latinx students. UC Davis would benefit from these efforts to train and admit talented Latinx students from the UC or CSU system to dramatically increase the numbers of Latinx graduate students, while aligning with faculty and staff advisors who encourage undergraduates to attend another institution for graduate school in order to acquire broader educational experiences.

In addition to supporting pipeline programs, UC Davis employs a graduate diversity team to focus on targeted recruiting efforts. Five full-time professionals, led by the two GDOs, employ recruiting strategies to lead and assist with campus pipeline programs, reach out to peer programs, recruit at national conferences, and guide electronic outreach and recruitment efforts. These and more expansive electronic outreach and graduate preparation efforts show great promise in developing Latinx talent. 
Although preparing Latinx students for graduate school is key to increasing doctoral student numbers, Latinx families should also be incorporated into their children's success. In many Latinx first-generation families, parents may initially hesitate to allow a son or daughter to move away, particulary far from home to pursue even a bachelor's degree. Most realize that earning a college degree has value and is associated with well-paying jobs. But if Latinx undergraduates are the first to earn a bachelor's degree within their families, pursuing a graduate degree is a lesser-known option compared to becoming a physician, lawyer, or perhaps dentist, professions with twice the enrollment of academic programs.

UC Davis recognizes the value of family culture during undergraduate outreach events and campus visits, usually inviting the whole family to participate. But similar efforts are unfortunately uncommon among graduate outreach and recruitment activities. Given the need to increase undergraduate programming to learn and prepare for graduate school across large numbers of Latinx undergraduates, not only could graduate outreach begin early, it could also be offered when families come to visit UC Davis. Moreover, delivering information in Spanish would signal that the University understands the value of directly engaging with Spanish-speaking parents and family members. Consequently, Latinx parents would learn about graduate school alongside their children and together discuss options based on common understandings. In addition, involving Latinx faculty and role models in graduate information efforts can provide inspiration for Latinx students as they consider their futures. Although specific professional careers with high-earning potential are best known, a balanced approach to available options that includes academic and professional fields alike would help Latinx students and their families make informed decisions together about pursuing graduate degrees.

For both Latinx undergraduates and their families, understanding the relevance of graduate education to careers and future earnings deepens their knowledge about graduate education and its potential for both occupational advancement and longterm employment benefits. Deliberately demystifying what graduate school actually is - that is, why someone would want to attend such a school; master's versus doctoral degree tracks; and differences between academic and professional degrees-would provide a foundation for further exploration. Degree relevancy is very meaningful for Latinx students and their families, and could be successfully communicated through undergraduate career-exploration efforts that connect career aspirations with doctoral studies. Specifically connecting STEM graduate programs to relevant careers within academia and industry could help turn the dream of earning a $\mathrm{PhD}$ into a reality.

Latinx success in graduate school is critical to finishing the doctoral degree and to being successful on the academic job market. When provided with sufficient funding, Latinx students can thrive in graduate school environments that include culturally sustaining and applied STEM curricula, a range of relevant research opportunities, and diverse faculty role models and mentorship. Understanding the connection of curriculum to the overall structure of the doctoral program and to scientific outcomes and breakthroughs convey to Latinx students why the degree is worthwhile, particularly for students who might be second-guessing their decision to pursue one. 
For both new and continuing Latinx graduate students, securing valuable and relevant research opportunities can be a difficult process, one that inhibits learning and reduces competitiveness. Although each graduate program or faculty has its own way of "advertising" its research expertise and making research opportunities known, formal rather than informal approaches benefit both Latinx and URM graduate students in STEM fields and help prevent stalling before finding a research direction. For example, graduate programs that expect students to reach out to individual faculty about advising and research opportunities might include a rotation of faculty through graduate courses to discuss their subfields, development of sustained research projects, and research possibilities. As a result, every graduate student would have access to similar information about gaining research experience and working with specific faculty. A second, more common approach, but one not consistently employed across STEM fields, is for new graduate students to rotate among faculty research labs, thus being exposed to a multiplicity of research options they can revisit after completing their lab rotations. This second, more-formal approach would provide a wide view of research opportunities within students' graduate programs. Both strategies offer Latinx scholars exposure to research opportunities as well as potential faculty mentors, thereby reducing the possibility they will languish at the university without direction or healthy faculty mentorship.

\section{Admission with Equity}

In recent years, UC Davis has seen exponential growth in its Latinx undergraduate population, which is a result of an intentional strategy in undergraduate admissions. However, due to a very different admissions model, increases in enrollment by Latinx graduate students are relatively low. Undergraduate admissions are led by a team of top-level administrators and admissions professionals, but an analogous infrastructure does not exist for the majority of graduate and professional programs at UC Davis, much less in higher education as a whole. Since the passage of Prop. 209 in 1996, the University of California, with its commitment to public education and access, has slowly developed undergraduate admissions practices that combine qualitative and quantitative metrics to consider holistically applicants' background and preparation. The development of holistic admission practices, coupled with the strategies and skills of well-trained, year-round professional staff, has resulted in an increasingly diverse, prepared, and competitive undergraduate student body.

Undergraduate admissions practices contrast starkly with those of graduate admissions, which are the purview of faculty senate members within each graduate program or group. Admitting graduate students is considered a component of faculty self-governance, thus faculty may resist any attempt to modify the process by others.

Broadly speaking, graduate admissions committees meet annually, often with limited to no training, to review applications and decide whom to admit and fund, 
with departmental and disciplinary cultures at play. The first review may be accomplished with as few as one or two persons, who quickly narrow the number of applications to be read. Particularly in STEM fields and within some professional schools, it is within this first round of review that standardized test scores, overall grade point averages (GPAs), and undergraduate institutional prestige are heavily considered, thus contributing to the elimination of nearly all women and URMs in STEM (Miller \& Stassun, 2014). Moreover, graduate admissions committees and leadership regularly change from year to year. Consequently, there is little time to develop new or even to update ongoing graduate admissions policies and procedures in a landscape that prioritizes faculty research above teaching and service. Consequently, UC Davis' undergraduate admissions are founded on a structural model that is inherently different from how graduate admissions take place at the university and at similar research institutions.

Although most graduate admissions processes occur as described above, a new equitable and inclusive approach to the graduate admissions process is taking root at UC Davis, one based in scholarship and faculty involvement and demonstrating promise for all fields, including STEM. The Alliance for Multi-Campus Inclusive Graduate Admissions (AMIGA) (https://www.projectamiga.org/; https://www.pro jectamiga.org/) teams two University of California graduate divisions - at UC Davis and UCLA - to collaborate with graduate program chairs, faculty, colleagues, and staff to incorporate holistic review methods into their graduate admission processes. With support from the Andrew W. Mellon Foundation, the project is an outcome of a seed grant that examined holistic review and its potential to support equity, inclusion, and diversity at four UC campuses.

The AMIGA project addresses ways that current graduate admissions processes can raise barriers to accessing graduate education. Participants collaborate to pilot more inclusive and equitable graduate admissions, drawing on scholarship and sharing best practices that include addressing faculty development to do the following:

- Achieve diversity in a Prop 209 environment,

- Contextualize GPAs,

- Develop and use rubrics,

- Deemphasize or eliminate standardized test scores, and

- Reduce unconscious bias.

Participating departments and programs aim to understand how a broad range of admissions criteria predicts successful outcomes in graduate education. Ultimately, AMIGA's goal is to develop new holistic graduate admissions methods that spark conversations about student diversity and the role of universities in fostering equity and inclusion and that lead to evidence-based institutional change, resulting in increased graduate student diversity. A second initiative, California Consortium for Inclusive Doctoral Education (C-CIDE) partners five UC campuses and promotes holistic review through faculty development in a small number of STEM fields. In addition UC Davis' participation, four additional UCs participate- UC Berkeley, UC Irvine, UC Santa Barbara and UC San Diego. 
Both the AMIGA and C-CIDE projects are having a powerful effect in introducing and supporting holistic graduate admissions processes campus-wide, including in STEM fields. With nearly three years of advocating for holistic graduate admissions campus-wide, UC Davis is beginning to experience admissions successes and increases in both Latinx and URM graduate student numbers.

The large number of international graduate student applicants to UC Davis ultimately also influences the number of domestic URM graduate students admitted each year. In the 2017-2018 academic year, graduate students identified as $40 \%$ white/Caucasian, 30\% International, 14\% Asian American, 10\% Latinx/Chicanx, $3 \%$ Black/African American, 1\% Native American, and 1\% who identified as Other. Similarly, UC Davis faculty is $27 \%$ international. With its significant numbers of international faculty, learning-development modules on Prop.209 and domestic race and ethnic issues may be warranted because of faculty's in experience with the U.S. educational context.

URM graduate students face unique challenges, but the challenges are even more complex when students are also first-generation or undocumented or both. While UC Davis has only a few years of data about first-generation applicants and admittees, the data are instructive. First-generation graduate applicants are on the rise, from about 1,000 in 2016 to 1,541 in 2019. Of UC Davis' first-generation students in 2018, some $43 \%$ come from URM groups. Moreover, first-generation students are admitted at lower rates, but enroll at higher rates when admitted. Interestingly, first-generation graduate students are twice as likely to take out student loans. Taken as a whole, these data imply the need to consider how first-generation applicants can be identified, and how students who are both first-generation and URMs can be supported, given the complex circumstances both groups encounter.

Beyond the category of first-generation applicants, a growing number of undocumented students are applying to graduate school at UC Davis and at similar research institutions. Although their status is not easily identified and their numbers seem relatively small at present, the numbers and needs will only continue to grow. Already, Graduate Studies, Campus Counsel, the AB540 and Undocumented Student Center, and individual graduate programs and groups at UC Davis have encountered challenging questions related to their admissions, California residency, financial support, ability to work, and legal methods of support. These undocumented graduate school applicants are largely Latinx students who have lived most their lives in the United States and have dreams similar to those of other children of immigrants: dreams to access higher education and then to prosper. UC Davis, along with other UC campuses, are quickly learning the extent of support in the current moment, but are also strategizing and planning how support can expand in future years. At the very least, UC Davis needs to identify multiple models of financial support for undocumented students, no matter their statuses.

Increasing financial support for graduate students and improving the climate of their social and academic environments have long been compelling goals for campus leadership. With the new UC Davis Graduate Student Center at Walker Hall opening in 2020, Latinx as well as URM graduate students will have access to study, meet, and gather in a convivial space with peers from across campus. 
The campus's pioneering initiatives to address graduate student diversity promise to increase the numbers of Latinx graduate students in STEM and to diversify the academic pipeline as a whole. The initiative to employ graduate diversity officers to address recruitment, admissions, and success is building talented pools of URM applicants and supporting them as graduate students. A second initiative, UC Davis's holistic graduate admissions project called AMIGA, can potentially influence faculty to embrace critical improvements in how applicants are evaluated and admitted, which in turn can open the doors to more Latinx women and URM students in STEM fields. Finally, envisioning and then erecting the Graduate Student Center at Walker Hall demonstrates the UC Davis' commitment to both graduate student success and the larger UCD community.

\section{Lessons Learned and Reflections for the Future}

The convergence of ADVANCE's institutionalization with UC Davis's HSI vision developed in 2018 has created an opportunity to reflect on how the University of California, and UC Davis in particular, can deepen its commitment to a broad academic diversity project. This has involved extending the focus on pre-hiring to the graduate and professional student pipeline, and also looking more closely at post-hiring, to consider how diversity and inclusion are connected to equity in higher education. That is, it must ask several critical questions: What is the role of an academic diversity project in creating a sense of belonging for all students, both undergraduate and graduate? How is such a project connected to teaching excellence and innovation that considers culturally-sustaining curricula, pedagogies, and even assessment practices? How is such a project connected to improving the ability of higher education to adequately prepare future leaders and professionals so they can fill persistent gaps in the workforce? How is such a project changing which research questions are prioritized and how that research is conducted to ensure it addresses the needs of underserved communities?

Quite frankly, at UC Davis and even at most institutions nationwide, we are still at the very beginning of responding to these difficult questions. Anecdotally, we certainly know that many faculty of color - though not necessarily all of them, and not them exclusively_are doing equity work for our students, undergraduate and graduate alike. They often feel overwhelmed by that awesome responsibility and undervalued in their contributions. It is vital, then, to clarify that an academic diversity project, if it is to be serious, must move beyond simply hiring a handful of faculty of color slowly over time and must ask, instead, how the university simultaneously must grow in ways that integrate and then cultivate the new voices and values brought by a more-diverse academic workforce and student body.

There is no question that growing the academic diversity pipeline, such as is already occurring at UC Davis, promises to increase the available pool of more diverse faculty nationwide, while at the same time attempting to change an institutional culture that seeks to redefine why diversity matters. As demonstrated in 
this chapter, for example, holistic admissions, when well done, promises to increase graduate student diversity and change the culture of who is excellent and belongs in the academy. Similarly, questioning the impact of long-held values-such as a bias against a homegrown graduate pipeline - seen through an equity lens focusing on, for instance, access and community values, calls for reexamining why graduate and professional education matters in the first place. Such efforts are not solely about cultivating a diversity of viewpoints but also about fostering a professional and academic trajectory rooted in family and community.

When an academic diversity project is connected to equity goals, it becomes crystal clear that the project is simultaneously increasing representation and changing culture. An approach to academic diversity that is solely a "numbers game" is achievable, but it will never lead to deeper change. As described in this chapter, many graduate students at UC Davis, not unlike faculty of color, are grappling with academic isolation and lack a sense of belonging that likely compromise their own trajectoryand possibly ensure their future exit from the faculty pipeline if they find they cannot see themselves thriving in that role.

\section{Conclusion}

The implications of seeking cultural changes alongside the academic diversity project often means that those changes, in addition to being intentional, must be methodical and must involve key stakeholders in the project. For this reason, while an effective holistic admissions process in graduate education requires many champions, ranging from funders to higher-education leaders, in the end it must be a faculty project. Faculty who educate graduate students must learn to recognize and value the various contributions that students who have traditionally been left out of the academic pipeline have something to offer. That is, beyond becoming just like them, their very presence and diversity in fact redefines excellence.

Acknowledgements We thank Laura Cerruti and Claudia Patricia Escobar for their invaluable assistance with editing, data, and ideas.

\section{References}

Aldana, R., \& Reed, R. (2019). Investing in rising scholars and serving the State of California: What it means for UC Davis to be a Hispanic serving Institution. Retrieved from https://diversity.ucd avis.edu/sites/g/files/dgvnsk731/files/inlinefiles/HSITaskForceReport_2019March29.pdf

Eligibility Designations and Application for Waiving Eligibility Requirements, 84 Fed. Reg. 451-454. (2019). Retrieved from https://www.federalregister.gov/documents/2019/01/29/201900251/eligibility-designations-and-applications-for-waiving-eligibility-requirements-programsunder-parts 
Excelencia in Education. (2019). Hispanic Serving Institutions (HSIs). Accessed April 20, 2019. https://www.edexcelencia.org/research/hispanic-serving-institutions-hsis

Garcia, G. A. (2018). Decolonizing Hispanic-serving institutions: A framework for organizing. Journal of Hispanic Higher Education, 17(2), 132-147. https://doi.org/10.1177/153819271773 4289

Integrated Postsecondary Education Data System (IPEDS) Data Collection System 2019-20, 12month Enrollment Full Instructions. https://surveys.nces.ed.gov/ipeds/VisInstructions.aspx?sur vey $=9 \&$ id $=30069 \&$ show $=$ all\#chunk_1138

Kaskle, B., Leicht, K., \& Hitlin, S. (2012). Promoting workplace longevity and desirable retirement pathways within academic institutions. Retrieved from https://www.tiaainstitute.org/sites/default/ files/presentations/2017-02/ti_promotinglongevity0312.pdf

Laden, B. V. (2001). Hispanic-serving institutions: Myths and realities. Peabody Journal of Education, 76(1), 73-92.

May, G. S. (2018a). Highlights from the State of the Campus Address: "We are on the Rise." Retrieved from https://www.ucdavis.edu/news/state-campus-we-are-on-rise

May, G. S. (2018b). Presentation: State of the Campus, Representative Assembly, UC Davis Academic Senate. Retrieved from https://leadership.ucdavis.edu/sites/g/files/dgvnsk1166/files/ inline-files/SOC_GM_Mar1.gsm_.cjb_.2.pdf.x

Miller, C., \& Stassun, K. (2014). A test that fails. Nature, 510(7504), 303-304.

Posselt, J. R. (2016). Inside graduate admissions: Merit, diversity, and faculty gatekeeping. Cambridge: Harvard University Press.

Rockwell, S. (1999). Campus looks into faculty hiring and promotion. UC Davis Dateline, Retrieved from https://www.ucdavis.edu/news/campus-looks-faculty-hiring-and-promotion/

Steele, C. M., \& Aronson, J. (1995). Stereotype threat and intellectual test performance of African Americans. Journal of Personality and Social Psychology, 69(5), 797-811.

Title 20-Education, 20 U.S.C. §1101a. (2015). Retrieved from https://www.govinfo.gov/app/det ails/USCODE-2015-title20/USCODE-2015-title20-chap28-subchapV-partA-sec1101a

UC Davis Diversity and Inclusion Strategic Vision. (2017). https://diversity.ucdavis.edu/sites/g/ files/dgvnsk731/files/inline-files/Diversity\%20and\%20Inclusion\%20Strategic\%20Vision\%20P lan\%20June\%2029\%202017.pdf

University of California Office of the President (UCOP). (2019). Infocenter. Fall enrollment at a glance. Retrieved from https://www.universityofcalifornia.edu/infocenter/fall-enrollmentglance. Fall enrollment at a glance. Retrieved from https://www.universityofcalifornia.edu/inf ocenter/fall-enrollment-glance. Workforce diversity. Retrieved from https://www.universityofcal ifornia.edu/infocenter/uc-workforce-diversity. Doctoral program data. Retrieved from https:// www.universityofcalifornia.edu/infocenter/doctoral-program

U.S. Census Bureau. (2019). Educational Attainment in the United States 2018. Retrieved from: https://www.census.gov/data/tables/2018/demo/education-attainment/cps-detailed-tables.html

White, B. P. (2016). "Beyond a deficit view." Inside Higher Ed, April 19, 2016. https://www.ins idehighered.com/views/2016/04/19/importance-viewing-minority-low-income-and-first-genera tion-students-assets-essay

White House Initiative on Educational Excellence for Hispanics. (2014). Hispanics and STEM Education. Retrieved from https://sites.ed.gov/hispanic-initiative/files/2014/04/WHI EEH-STEM-Factsheet.pdf 
Open Access This chapter is licensed under the terms of the Creative Commons Attribution 4.0 International License (http://creativecommons.org/licenses/by/4.0/), which permits use, sharing, adaptation, distribution and reproduction in any medium or format, as long as you give appropriate credit to the original author(s) and the source, provide a link to the Creative Commons license and indicate if changes were made.

The images or other third party material in this chapter are included in the chapter's Creative Commons license, unless indicated otherwise in a credit line to the material. If material is not included in the chapter's Creative Commons license and your intended use is not permitted by statutory regulation or exceeds the permitted use, you will need to obtain permission directly from the copyright holder.

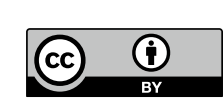

